\title{
TRANSPORT, LOGISTICS AND PACKAGING OF ITER COMPONENTS
}

\author{
Olivier Guérin, Bruno Couturier, Akko Maas and EISS Team* \\ Association Euratom-CEA, DSM/DRFC, CEA Cadarache, 13108 Saint-Paul-lez-Durance, \\ France \\ Phone: +33442257440 - Fax: +33442256375-email: olivier.guerin@cea.fr
}

\begin{abstract}
Cadarache, the European site for ITER, is located at around $50 \mathrm{~km}$ as the crow flies from the sea. The feasibility of the transport of large and heavy ITER components has thus been thoroughly studied. These studies have covered the following items:

- Possible itineraries between the most convenient harbour (Fos) and Cadarache;

- Packaging (in particular for the largest and heaviest components);

- Means of transport (two types of trailers allowing to avoid lifting and load transfers);

- Logistics (analysis of transfer kinematics, including temporary storage);

- Administrative procedures and planning for the road adaptation, taking benefit of the recent successful implementation in the South-West of France of an itinerary for the Airbus A380 components.
\end{abstract}

These studies, performed between 2001 and 2003, led to a viable solution, with a reasonable cost, fully supported by the French authorities. The planning necessary to implement the road modifications is also fully compatible with the expected dates of ITER components delivery.

\section{Keywords}

ITER - Cadarache - site preparation - transport of large and heavy components, packaging

\section{Acknowledgements}

The authors want to thank particularly Thierry Décot, CETE Méditerranée; Pierre Garnier, DDE Bouches-du-Rhône; Gilbert Raust, DRE Midi Pyrénées; Roger Calet, Mammoet Fostrans; Benoit Giraud, Framatome-ANP for their contributions to these studies.

\footnotetext{
* European ITER Site Studies.
} 


\section{Introduction}

The construction of ITER will be an important challenge over the coming years. Components for the machine will be manufactured by all ITER partners, in factories around the world. These components, some of them very large and heavy, will have to be transported to the ITER construction site.

As largest components to be transported, the dimensions and the mass of the Vacuum Vessel Sectors, the Toroidal Field Coils and the Crane Beams have been taken into consideration to determine all the needs.

In case of the European site for ITER, at Cadarache in the South-East of France, the transport will have to be ensured over an itinerary of around $100 \mathrm{~km}$, from the nearest industrial harbour to the site.

\section{Itinerary}

The itinerary studies have been performed by CETE (State Road Design Office) in 3 steps:

- Analysis of all the possibilities of transport from the Mediterranean sea to the site,

- Choice of a reference itinerary, avoiding overpass bridges and road creations,

- Optimisation of the reference itinerary, by studying local alternatives.

This optimised itinerary allows minimising the main road improvements to the following:

- enlargement of existing roads or use of temporary tracks at Lançon and Peyrolles,

- rectification of bends at "Fontaine du Garri", which will also improves the road safety,

- enlargement by an overhang at "Défilé de Mirabeau", which will simplify crossings.

A view of the reference itinerary and the local alternatives is shown in figure 1.

The components will arrive at Fos harbour by sea-going ships. To offload the heaviest components (in particular VV Sectors and TF Coils), the ships will be geared or roll-on/rolloff vessels. A dedicated zone will be used for temporary storage, to allow flexibility for logistics.

The components will then be handled by adequate trailers to be loaded onto a barge, which will cross the "Étang de Berre" to the unloading point, by the existing channel allowing a draught of $7 \mathrm{~m}$. To simplify operations as well as for safety reasons, it is recommended to use a roll-on/roll-off method, in particular on the dock to be created at the harbour of "la Pointe".

\section{Packaging}

The packages designed for VV Sectors and TF Coils can be slung and jacked, in order to allow roll-on/roll-off, transport and storage operations, but also lifting operations on the ITER site. They are designed to be generic and include: 
- Handling Skid Support and closed container (corrosion protection during sea transport),

- Fixation, anti-rocking devices and adjustable pads, coherent with $30^{\circ}$ tilt of the ship).

A tilted support for the TF Coils will allow them to have a similar width as the packages of the $40^{\circ} \mathrm{VV}$ Sectors. The horizontal lifting of the TF Coils has also been studied and can be done on site by using a specific rotating tool with the Tokamak building main crane (see Figure 2).

\section{Trailers}

The 28 heaviest components (9 VV Sectors and 18 TF Coils +1 spare) will be transported by Self-Propelled Modular Transporters, which are multidirectional over $360^{\circ}$. Each transport will last 3 nights (at $3.5 \mathrm{~km} / \mathrm{h}$ on average), but only one day will be necessary to bring the trailers back to the starting point, by disassembling the Self-Propelled Modular Transporters into modules, carried on a classic trailer.

The advantages of such Self-Propelled Modular Transporters (see figure 3) are:

- very flexible during operations and minimum steering radius (even 0),

- the centre of rotation can be programmed at any preferable location,

- no need of tractors and possibility to jack the load over more than 0.5 metre,

- great stability and capability to spread the load by hydraulic axle compensation.

For all other components (such as Crane Beams, Large HV Transformers, Central Solenoid Modules, etc.), it is recommended to use multi wheel conventional trailers, with prime movers. Transports will take only one day with such trailers. In case of the longest component (46.9 meter), the convoy remains versatile enough thanks to two turn tables (figure 4).

\section{Logistics}

In close collaboration with the ITER International Team, who supplied the list of the largest and heaviest components to transport, approximately 300 of them have been identified as components which need a "convoi exceptionnel", according to French transport regulation.

ITER components have been divided into four categories, depending on their mass, and also their length and width. One third of them, those lighter than 90 ton, can use the roads already classified for "convoi exceptionnel" to go from Fos harbour to Cadarache. No modifications are needed for these "standard" components. All other components $(\sim 200)$ will take a rollon/roll-off barge to get into the "Etang de Berre", at the harbour of "la Pointe".

The longest and one of the first component to be transported (the 4 Crane Beams) can take the motorway without need for modification, pass under its bridges and through the tunnel at "Mirabeau". As many of the other components are too high to take the tunnel, an overhang will be erected in the "défilé de Mirabeau", which is the most important improvement needed 
along the entire itinerary. This widening of the road will also improve the traffic safety in this area.

The components lighter than 120 tons can take the existing bridges over the motorways. To avoid reinforcement of these three bridges (which would disturb the motorway traffic during several months), about fifty components heavier than 120 tons will cross it at the same level, so the disturbance will only take place for a few minutes, in the middle of the night.

\section{Experience}

A recent example illustrates the capability of Europe to realise such a challenge: the transport of Airbus A380 (the future world's largest aircraft) components between Bordeaux and Toulouse, in the South-West of France.

The components (each aircraft is divided in six parts), which are longer and higher than ITER main components, are manufactured in several European countries, shipped to Bordeaux, then transported by river $(96 \mathrm{~km})$ and by road $(240 \mathrm{~km})$ to Toulouse, where assembly of the first model started in April 2004. The frequency will be about 1 convoy per week from 2008.

The planning was very tight between the decision to launch the industrial programme in December 2000 and the first test transport in November 2003 (see figure 5). All the steps have been successfully completed, from the administrative procedures to the road and bridge modifications, including the respect of the foreseen budget and planning.

\section{Conclusion}

The feasibility of the transport of ITER components to the European site in Cadarache has been demonstrated as well as the capability of Europe to manage this important challenge in due time. 


\section{List of figures}

Figure 1: Reference Itinerary and Alternatives for Transport of ITER Components from Fos Harbour to the Cadarache site $\mathbb{C}$ IGN

Figure 2: Suggestion of Lifting and Manipulation Tool for Toroidal Field Coil

Figure 3: Example of Self-Propelled Modular Transporters for Transport of Vacuum Vessel Sectors and Toroidal Field Coils

Figure 4: Transport Configuration for Crane Beams

Figure 5: Transport of AIRBUS A380 components 
Figure 1: Reference Itinerary and Alternatives for Transport of ITER Components from Fos Harbour to the Cadarache site @IGN

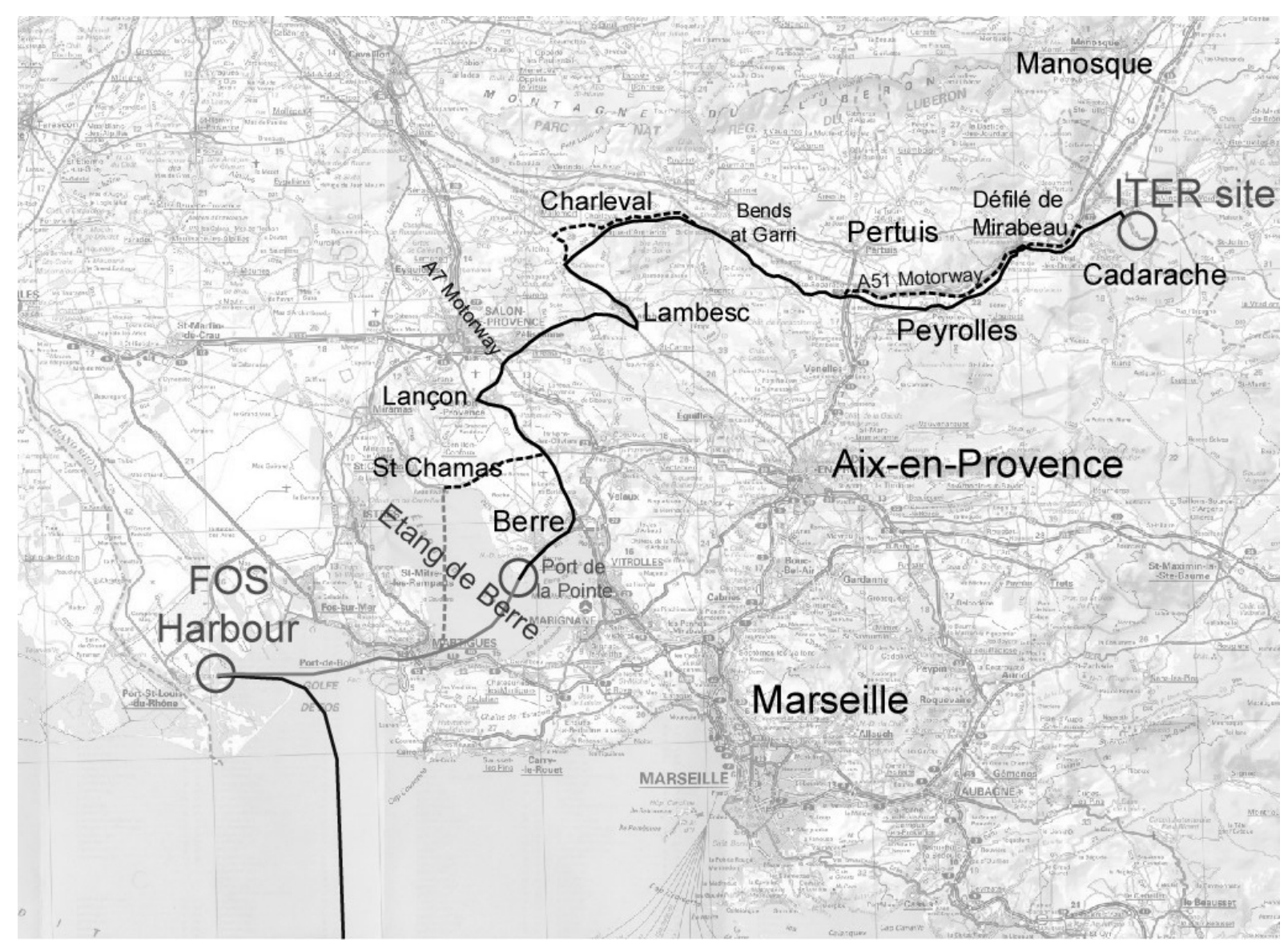


Figure 2: Suggestion of Lifting and Manipulation Tool for Toroidal Field Coil

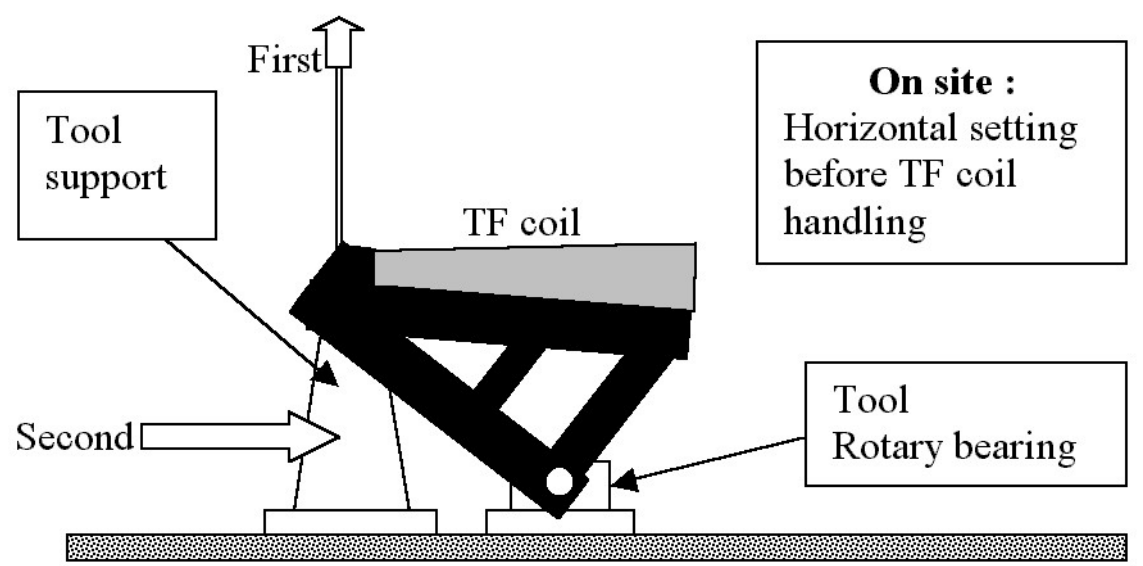


ID 522

Figure 3: Example of Self-Propelled Modular Transporters for Transport of Vacuum Vessel Sectors and Toroidal Field Coils




ID 522

Figure 4: Transport Configuration for Crane Beams

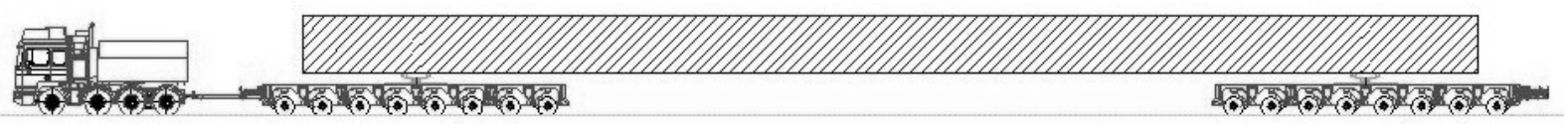


Figure 5: Transport of AIRBUS A380 components

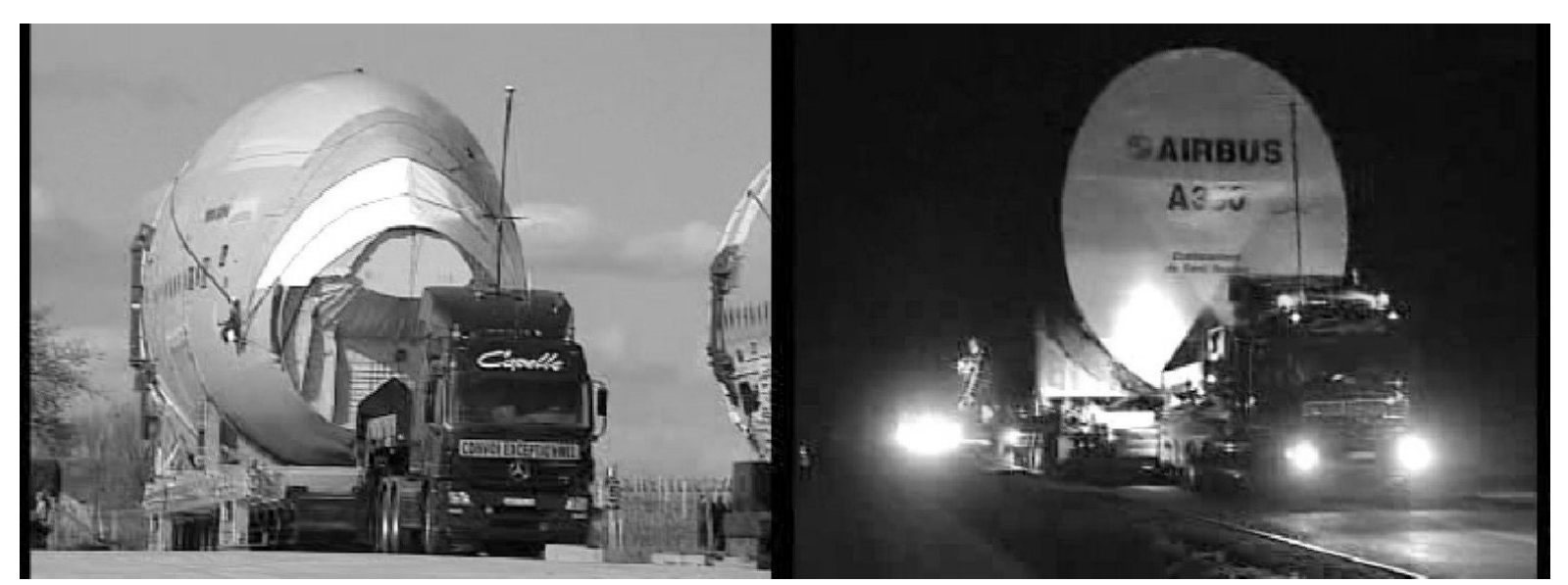

